\title{
Transient myeloproliferative disorder and non-immune hydrops fetalis in a neonate with trisomy 21
}

Hong Kong Med J 2014;20:78.e3-4

KL Hon ${ }^{*, 1}$, TY Leung ${ }^{2}$

DOl: 10.12809//kmj133750

A 39-year-old Rhesus-positive mother had been well. She had been screened low risk (1:2496) for Down syndrome (DS) at the first-trimester combined screening in late 2012. The fetal morphology scan at 20 weeks of gestation was normal. Nevertheless, an ultrasound scan at 32 weeks of gestation showed bilateral pleural effusions. Amnioreduction and left pleural tap yielded $35 \mathrm{~mL}$ of pleural chyle. There was no evidence of a viral infection. A girl was delivered

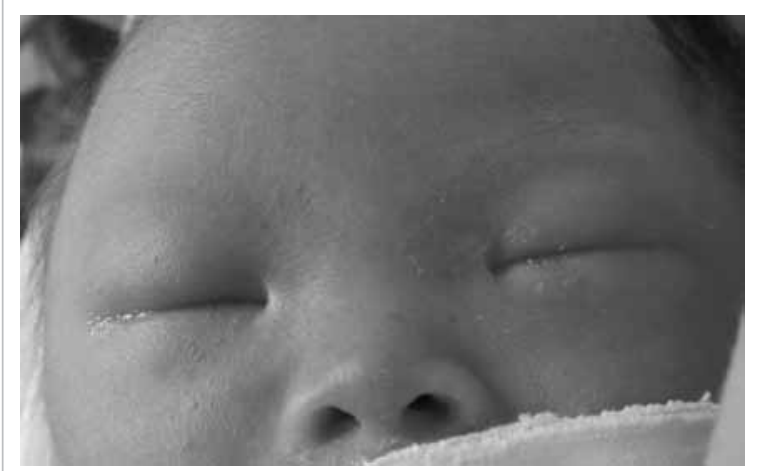

FIG I. Neonate immediately intubated following delivery

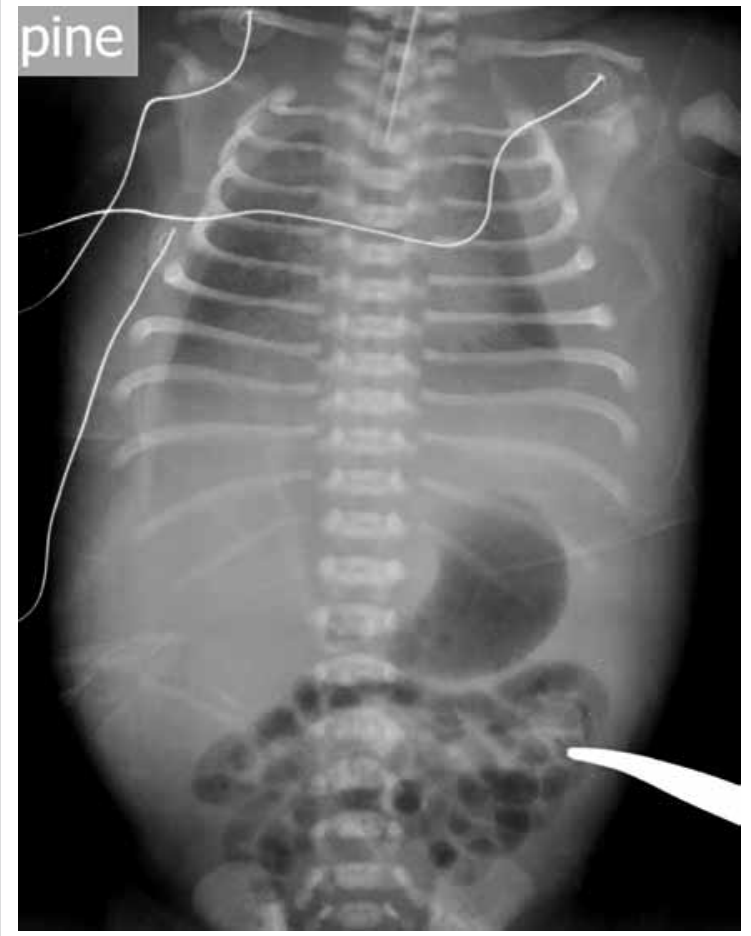

FIG 2. Bilateral pleural effusions at 33-weeks-6-days of gestation by emergency caesarean section because of recurrent fetal pleural effusions. The neonate was mildly oedematous with a distended abdomen and hepatomegaly (Fig 1). The baby was intubated and transferred to the neonatal intensive care unit (ICU) for further management. Pleural effusions (Fig 2) were drained by pleural tapping and chest drains. Echocardiography showed that her cardiac structure and function appeared normal, but a high pulmonary pressure and a patent ductus arteriosus were evident. Plasma total protein was $35 \mathrm{~g} / \mathrm{L}$ (reference range, $65-82 \mathrm{~g} / \mathrm{L}$ ) and albumin $22 \mathrm{~g} / \mathrm{L}$ (reference range, 35-52 $\mathrm{g} / \mathrm{L}$ ). The highest blood white cell count was $84.2 \times 10^{9} / \mathrm{L}$ (50\% blasts). What is the underlying diagnosis for this infant's chylothoraces, hypoproteinaemia, and leukocytosis?

1. Immune hydrops

2. Trisomy syndrome

3. Congenital infection

4. Congenital lymphoma

5. Inborn error of protein metabolism

In the neonatal ICU, she improved with full intensive support (mechanical ventilation, thoracostomy drainage of pleural fluids, and treatment with intravenous octreotide). Trisomy 21 $(47, \mathrm{XY},+21)$ was subsequently confirmed following chromosomal evaluation.

Hydrops fetalis (fetal hydrops) is a serious fetal condition defined as an abnormal accumulation of fluid in two or more fetal compartments, and includes ascites, pleural effusion, pericardial effusion, and skin oedema. ${ }^{1}$ It may be due to immune or nonimmune aetiologies. ${ }^{1,2}$ Rhesus isoimmunisation is the commonest immune aetiology, and alphathalassaemia is a non-immune cause. ${ }^{1}$ Immediate diagnosis of other aetiologies is often not possible without extensive investigations. A prompt spot diagnosis of DS was made in this neonate with typical facial features, which obviated the need for an extensive search for an underlying aetiology and enabled target therapies to be instituted (Fig 1). Trisomy 21 is a known association with hydrops fetalis and myeloproliferative disorder. ${ }^{1,2}$

Transient myeloproliferative disorder (TMD) is a self-limiting disorder characterised by leukocytosis and the presence of megakaryoblasts in the peripheral blood and bone marrow, anaemia, thrombocytopenia, and organomegaly. It occurs in 
approximately $10 \%$ of newborn infants with DS. ${ }^{2}$ Hepatic fibrosis is encountered in the severe form of TMD with DS, and is characterised by diffuse intralobular sinusoidal fibrosis and extramedullary haematopoiesis. ${ }^{3}$ Although TMD in most patients resolves spontaneously within the first 3 months of life, in a few severe cases there can be hepatic fibrosis or cardiopulmonary failure. Acute megakaryocytic leukaemia (AML-M7) is noted in 20 to $30 \%$ of babies with DS and TMD within the first 4 years of life. ${ }^{4}$ Cytokines produced by megakaryocytes (including transforming growth factor-beta, platelet-derived growth factor, and platelet factor 4) could be responsible for the pathogenesis of TMD. ${ }^{3}$ The imbalance between intravascular or capillary hydrostatic pressure and transcapillary filtration may be responsible from hydrops fetalis. ${ }^{2-5}$

Prompt recognition of the facial features of DS is important to facilitate immediate diagnosis and management of this neonate with hydrops fetalis.

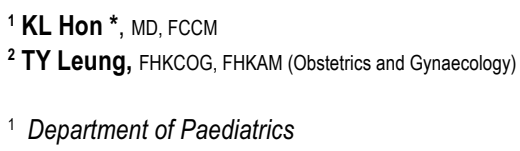

${ }^{2}$ Department of Obstetrics and Gynaecology

The Chinese University of Hong Kong, Prince of Wales Hospital, Shatin, Hong Kong

* Corresponding author: ehon@cuhk.edu.hk

\section{References}

1. Bellini C, Hennekam RC, Fulcheri E, et al. Etiology of nonimmune hydrops fetalis: a systematic review. Am J Med Genet A 2009;149A:844-51.

2. Oetama BK, Tucay RF, Morgan DL. Pathologic quiz case: nonimmune hydrops in a newborn. Down syndrome with acute (transient) leukemia. Arch Patho Lab Med 2001;125:1609-10.

3. Hongeng S, Pakakasama S, Hathirat P, Phuapradid P, Worapongpaiboon S. Diffuse hepatic fibrosis with transient myeloproliferative disorders in Down syndrome. J Pediatr Hematol Oncol 2000;22:543-4.

4. Al-Kasim F, Doyle JJ, Massey GV, Weinstein HJ, Zipursky A, Pediatric Oncology Group. Incidence and treatment of potentially lethal diseases in transient leukemia of Down syndrome: Pediatric Oncology Group Study. J Pediatr Hematol Oncol 2002;24:9-13.

5. De Groot CJ, Oepkes D, Egberts J, Kanhai HH. Evidence of endothelium involvement in the pathophysiology of hydrops fetalis? Early Hum Dev 2000;57:205-9. 